Article

\title{
Between Science Education and Environmental Education: How Science Motivation Relates to Environmental Values
}

\author{
Mona L. Schönfelder *(i) and Franz X. Bogner(D) \\ Centre of Math \& Science Education (Z-MNU), Department of Biology Education, University of Bayreuth, NW1, \\ 95447 Bayreuth, Germany; franz.bogner@uni-bayreuth.de \\ * Correspondence: mona.schoenfelder@uni-bayreuth.de
}

Received: 5 February 2020; Accepted: 28 February 2020; Published: 4 March 2020

check for updates

\begin{abstract}
Science education and environmental education are important gates to prepare the next generation for our society's current and upcoming challenges. While in the informal sector, environmental education acts independently, on the formal side, science education hosts environmental issues within its interdisciplinary context. As both educational efforts traditionally bear different emphases, the question may arise of whether formal science classes can act as an appropriate host. Against the background of the declining motivation to learn science in secondary school, possible synergies between both educational efforts may have vanished. For an investigation of such linkages between science motivation and environmental perception, we monitored adolescents' motivation to learn sciences and their environmental values. By analyzing data from 429 Irish secondary school students, we reconfirmed existing scales by using confirmatory factor analysis (CFA) and investigated potential relations via SEM. Besides gender differences, we identified a significant relationship between positive 'green' attitude sets and the individual motivation to learn science-positive environmental preferences predict a high science motivation, primarily intrinsic motivation. Taking advantage of this relationship, individual motivation may find support from environmental educational initiatives with the focus on green values. Especially girls, who evidentially tend to have a lower motivation in science learning, may be addressed in that way.
\end{abstract}

Keywords: 2-MEV model; confirmatory factor analysis; environmental attitudes; gender; science motivation; secondary education; structural equation modeling

\section{Introduction}

The major challenges of today's society, such as climate change, water and food security, as well as biodiversity loss, involve efforts to protect and save the environment. Coping with these 'wicked' problems requires education and engagement [1]. As a result, environmental education and education for sustainable development become increasingly important [2]. Considering only the formal education sector, environmental education, however, still struggles for curriculum time embedded primarily in science or biology classes [3]. Historically, environmental education entered school curricula in the 1970s when concerns about environmental degradation were broadly discussed on a global level [4]. The explicit goals and objectives of environmental education were described in documents such as the Belgrade Charter [5] and the Tbilisi Declaration [6]. The latter had remarked that education was a major trigger for utilizing the findings of science and technology and asked for it to have a leading role in creating an awareness and a better understanding of environmental problems, thus anchoring environmental education within science education. Over 40 years later, both environmental education and science education have evolved considerably. While science education primarily 
builds upon acquiring knowledge and teaching skills, environmental education, within a formal and informal context, focuses additionally on raising awareness and even on changing behavior, often in a more emotional context [2]. Nevertheless, authors such as Gough [4] have already questioned science education as an appropriate host for environmental education, as their relationship can be characterized as 'distant, competitive, predatory-prey, and host-parasite' (p. 1203). Some science educators have even claimed an incompatibility between both sets, as the objective and rational character of science education cannot engage social issues as necessary within a holistic sense of environmental education. Instead of accepting these traditional orientations, Gough [4] appealed to both science and environmental educators to consider their educational goals not as static and monumental. Environmental education could rather function as enrichment for science education by introducing values and action in the sense of scientific literacy. Young people would be concerned about current environmental challenges, which might be pivotal in rekindling their interest in the relevance of science. Therefore, Wals and colleagues [2] indicated the potential of citizen science and ICT tools as upcoming trends that can be used to foster the needed convergence between science and environmental education-a convergence that is increasingly demanded in the face of the previously mentioned wicked challenges [1]. Due to the discrepancy that still exists between science education and environmental education, a closer look at students' personal views is needed to ascertain what extent the individual motivation to learn science might relate to environmental attitudes and values.

\subsection{Science Motivation}

Students' interest, motivation, and attitudes toward science were repeatedly investigated in educational research studies [7,8]. In general, the relationship between students and school science and technology is described as problematic, pointing to a decline of motivation, attitudes, and interest, especially linked with age and gender (in favor of boys). Especially, motivation to learn science is regarded as an interfering factor in the process of becoming a scientifically literate citizen [9]. Following the social cognitive theory of human learning described by Bandura [10], Glynn et al. [9] refined the traditional definition of motivation-motivation to learn science is 'an internal state that arouses, directs, and sustains science-learning behavior' (p. 1160). A motivated person 'is moved to do something' [11] (p. 54), which means in our context-moved to learn science. Motivation is not directly observable, but derivable from observed behavior or (self-) reports [12]. Besides people's level or amount of motivation, people vary in their orientation of motivation which 'concerns the underlying attitudes and goals that give rise to action' [11] (p. 54). Basically, intrinsic and extrinsic motivation need differentiation. Intrinsic motivation is defined as doing an activity (e.g., learning) for its inherent satisfaction, the enjoyment of the activity itself. Extrinsic motivation, in contrast, refers to doing something in order to attain some tangible outcomes, such as better career options or a good grade [11]. However, motivation as a multicomponent construct consists of many factors. One crucial attribute in the learning context is the self-determination referring to students' perception of their control of learning. A positive feeling of autonomy can come along with intrinsic motivation supporting academic performance [13]. Equally, self-efficacy plays an important role, which refers to the individual confidence in the ability to achieve desired results [10]. Similar to self-determination, self-efficacy is supposed to facilitate intrinsic motivation [11] and strongly predicts academic achievement [14].

Within the social cognitive learning theory, self-regulation is regarded as a crucial precondition for desired learning outcomes. As self-regulation can arise when students understand and control their motivation, cognition, and behavior, teachers and instructors should create learning environments in which behavior such as asking questions, studying, or help seeking is provoked [12]. The understanding of students' motivation toward science and related individual factors forms the basis for the creation of goal-oriented self-regulated learning environments in science education. This requires reliable and valid tools to assess motivation. Besides further instruments to quantify students' motivation toward science (for an overview, see [15]), the Science Motivation Questionnaire in its current version (SMQ-II) [9] captures a student's motivation as a multicomponent construct. 
The SMQ-II builds upon the social cognitive theory [10] as well as the self-determination theory [16] by combining internal and external motivational factors. The internal sub-factors include the inherent satisfaction of learning sciences (intrinsic motivation), the perceived competence in completing science-related tasks (self-efficacy) and the perceived autonomy referring to students' commitment and effort (self-determination). The external factors cover two dimensions of the motivation to learn science-learning because of the expectation of external compensation in the form of good grades (grade motivation) and learning because of the judgment of science as valuable for future career options (career motivation) [13]. Although the scale was originally developed to monitor motivation at university level, the suitability for (upper) secondary school level was also proven $[17,18]$.

Motivation toward science is regarded as a key element in science education and in acquiring scientific literacy [9]. Empirical studies have already proved the link between science motivation and academic performance [19-21]. While motivation toward science may affect learning processes, single factors of motivation in this context are related to individual characteristics such as personality traits [17], cognitive style [22], and interest [23], to name but a few. Potvin and Hasni [8] discussed these links in their review work in depth.

\subsection{Environmental Attitudes}

Pillars of educational initiatives within the environmental context are knowledge, attitudes, skills, and awareness, which form a person's environmental competence [5]. Since the anchoring of environmental issues in formal education, many research studies have dedicated their focus to the influences and interrelations between these elements with the overall aim of encouraging more pro-environmental behavior [24]. Strong predictors for conservational performance seem to be environmental attitudes [25] and connectedness to nature [26]. The effectiveness of educational methods and approaches in the environmental context is well documented (for an overview see [27]). In this regard, environmental knowledge $[28,29]$ can be acquired through educational settings that focus on intervening with positive environmental attitudes [30,31]. Although most of the investigated settings were settled in conventional classroom contexts [29] or residential outreach programs [32], to our knowledge there are no studies on the function of environmental attitudes in science classes.

For measuring adolescents' environmental attitude sets, the Two Major Environmental Value model (2-MEV) [33,34] is proved to be a valid and reliable tool and was applied in many research studies in the environmental context $[29,31]$. The model assesses the two orthogonal factors, preservation and utilization-the first refers to a person's intent to support nature, his or her care with resources as well as the inherent enjoyment of nature, and the latter covers a person's perspective on human dominance and altering nature [34]. Subsequent studies revealed that the utilization of nature had been considered as the exploitative usage of nature, whereas the appreciative usage of nature had been widely neglected. The two perspectives of utilization constitute two ends of a spectrum or are even opposites of each other [35]. Therefore, Bogner [36] extended the 2-MEV model by adding the dimension, appreciation, from an existing scale from Brügger and colleagues [37]. With the help of an exploratory factor analysis, it was shown that appreciation constituted a distinguishable factor, which was related to preservation, but not to utilization-a person who appreciates nature tends to have a preservative attitude and vice versa [36]. Further studies using the 2-MEV in an educational context revealed that positive environmental attitude sets relate to learners' knowledge acquisition $[29,32]$ as well as to other individuals' characteristics [38].

\subsection{Purpose}

Motivation to learn science is a key element regarding a successful acquisition of scientific knowledge and literacy as well as regarding future career choices. Unfortunately, secondary school students, especially girls, show declining science motivation. On the other hand, environmental attitudes play a crucial role in environmental education, as positive values are a precondition for 
pro-environmental behavior. Environmental education approaches especially aim to foster positive attitudes and awareness toward nature.

The main purpose of our current study is therefore to analyze a potential relation between the motivation to learn science and environmental values in the context of possible synergies of science and environmental education. Thus, the objectives are threefold-first, to apply and confirm existing scales to monitor science motivation and environmental values with the focus on a secondary school sample; second, to analyze the relationship of both scale constructs; and third, to unveil potential gender differences.

\section{Materials and Methods}

\subsection{Sample}

Our sample consisted of 429 Irish school students. Overall, data from 19 classes from five different schools was collected. The mean age was 14.65 years $( \pm 1.89 \mathrm{SD})$, and $32.9 \%$ were female. The unequal distribution of boys and girls was due to collecting data in a separate boys' school. Participating schools, students, and their parents were informed about the anonymous and voluntary participation and provided their consent. Students completed a paper-and-pencil questionnaire during regular school lessons. We respected data privacy laws as we recorded our data pseudo-anonymously. Only the specific identifier number, based on gender, birth month, and year was included.

\subsection{Measures}

We applied the Science Motivation Questionnaire in its current version (SMQ-II) of Glynn and colleagues [9] consisting of 25 items structured in five sub-scales (5 items each)-intrinsic motivation, career motivation, self-determination, self-efficacy, and grade motivation. The response pattern followed a 5-point Likert scale ranging from 5 (always) to 1 (never). We adapted the original wording in three items by deleting the additional wording "labs", as it was not relevant for our sample.

Second, the Two Major Environmental Values (2-MEV) scale was applied to monitor the two orthogonal dimensions, utilization (UTL) and preservation (PRE) [33,35], accompanied by the 'appreciation of nature' scale (APR) [37] in its shorter modified version [36]. UTL portrays an exploitative aspect of utilization, which covers preferences, e.g., to exploit resources and alter nature. APR, on the other side, complements the semantic meaning of utilization displaying a person's preference of an appreciative usage of nature. Both contrary aspects of utilization are part of someone's environmental attitude so that APR complements reasonably the 2-MEV. For each environmental value, we used 5 items to reach a balanced number of items in relation to the motivational sub-scales. The selection of items resulted from the principal component analysis described by Raab et al. [38], who used the same data set-the 5 highest loading items per factor were chosen. The respective response pattern also followed a 5-point Likert scale from 5 (totally agree) to 1 (totally disagree). A person with a positive attitude toward nature and the environment was expected to score high within APR and PRE and low regarding UTL [36].

\subsection{Statistical Analyses}

In order to examine the underlying research questions, this study was based on structural equation models conducted with R (Version 3.5.2). First, we performed confirmatory factor analysis (CFA) to assess the construct validity of the applied instruments. For the 2-MEV, we specified a model with the latent variables UTL, PRE, and APR to confirm the structure suggested by Bogner [36] (model 1). Moreover, the model fit of two alternative models were compared-a one-factor model with all 15 items (1a) and one with two latent variables summarizing the 'positive' attitudes PRE and APR (1b). Following conventional recommendations [39-41] multiple fit indices (chi2/df, root mean square error of approximation (RMSEA), standardized root mean square residual (SRMR), and comparative fit indices (CFI)) were used to test which model fitted best to our data. A good fit was 
indicated by chi2/df $<2$, RMSEA $<0.06$, SRMR $<0.08$, and CFI $\geq 0.90$. For the SMQ-II, we performed the same procedure following the original model [9] with five latent factors (model 2). In addition, we calculated the internal consistency of all variables (Cronbach's alpha). Examining gender differences, Bartlett factor scores were used for all specified latent variables to conduct independent sample $t$-tests. According to Field et al. [42], we calculated the effect size $r$, whereby effects were interpreted as 0.10 'small effect', 0.30 'medium effect', and 0.50 'large effect' [43].

We proceeded by performing structural equation models (SEM) to investigate the relationship between science motivation and environmental attitudes. In the first step, we tested the predictive ability of science motivation on environmental values. Therefore, we specified a causal higher-order model with 'Science motivation' as a latent second-order factor above IM, CM, SD, SE, and GM to avoid interferences due to multicollinearity [44]. Similar to the CFA, robust statistical methods with maximum-likelihood estimation were used as not all scales were normally distributed. Second, we tested if environmental values may be a predictor for the different aspects of the motivation toward learning science. In contrast to the previous model, 'Environmental values' were specified as a second-order factor above PRE, UTL, and APR and the same statistical methods were used. We decided to use two separate models testing the respective predictive ability (Science motivation/Environmental values) to get a better and clear view of the affected sub-scales of both instruments.

\section{Results}

\subsection{Measuring Environmental Values}

Confirmatory factor analyses were conducted for the suggested 2-MEV model [36] as well as for two alternative models and compared according to model fit. All described models showed

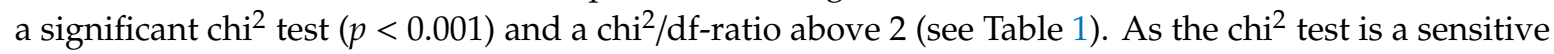
fit measure to large sample sizes ( $>200$ ) [45], we focused on additional fit indices for interpretation. The suggested model of Bogner [36], with the two orthogonal factors PRE und UTL accompanied by the APR scale (model 1), showed acceptable fit indices (RMSEA $<0.06$, SRMR $<0.08$, and CFI $\geq 0.90$ ). In contrast, both alternative models, more precisely the one-factor model with 15 items (1a) and the two-factor-solution (1b), had poor fit indices with values above the described thresholds. Due to model fit indices, the original could be accepted, whereas the two alternative models $1 \mathrm{a}$ and $1 \mathrm{~b}$ had to be rejected.

Table 1. Fit statistics for the original and alternative models of the confirmatory factor analyses.

\begin{tabular}{|c|c|c|c|c|c|c|c|}
\hline & & $\mathrm{chi}^{2}$ & df & $\mathrm{chi}^{2} / \mathrm{df}$ & CFI & RMSEA & SRMR \\
\hline \multicolumn{8}{|l|}{ Environmental values } \\
\hline 1 Original model & (APR, UTL, PRE) & 186 & 87 & 2.14 & 0.91 & 0.056 & 0.058 \\
\hline 1a One-factor model & (APR/UTL/PRE) & 462 & 90 & 5.13 & 0.63 & 0.110 & 0.104 \\
\hline 1b Two-factor model & (APR/PRE, UTL) & 329 & 89 & 3.70 & 0.76 & 0.088 & 0.084 \\
\hline \multicolumn{8}{|l|}{ Science motivation } \\
\hline 2 Original model & & 530 & 265 & 2.00 & 0.94 & 0.057 & 0.051 \\
\hline
\end{tabular}

In model 1, relevant items were assigned significantly to all high order values with standardized factor loadings ranging from 0.34 to 0.74 (see Figure 1). The factors APR and PRE showed a significant interrelation $(r=0.44)$, whereas UTL did not showed a significant covariance with APR or PRE. When calculating internal consistency, APR showed a good Cronbach's alpha of 0.81, UTL (0.62) and PRE (0.64) showed an acceptable reliability [46]. 


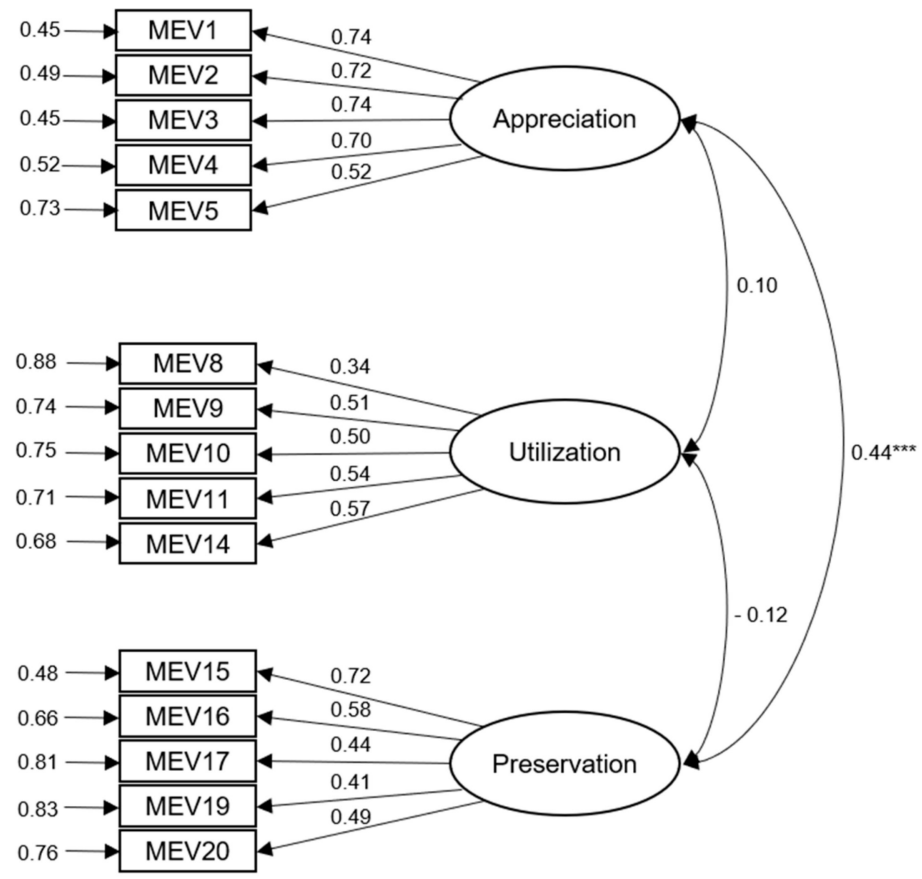

Figure 1. Confirmatory factor analysis of the Two Major Environmental Value model (2-MEV) (preservation and utilization) and appreciation of nature with standardized factor loading and covariance between the latent factors; ${ }^{* * *} p<0.001$.

We checked for gender differences by comparing Bartlett factor scores. Girls had a higher appreciation for nature than boys did (APR), wanted to preserve (PRE), but also to exploit (UTL) more (Table 2).

Table 2. Gender differences for environmental values and for science motivation.

\begin{tabular}{|c|c|c|c|c|c|c|c|c|}
\hline & \multicolumn{2}{|c|}{ Boys } & \multicolumn{2}{|l|}{ Girls } & \multirow[b]{2}{*}{$t$} & \multirow[b]{2}{*}{$d f$} & \multirow[b]{2}{*}{$p$} & \multirow[b]{2}{*}{$r$} \\
\hline & $M$ & $S E$ & $M$ & $S E$ & & & & \\
\hline \multicolumn{9}{|c|}{ Environmental values } \\
\hline Appreciation & -0.15 & 0.05 & 0.31 & 0.08 & -4.90 & 387 & $0.000^{* * *}$ & 0.24 \\
\hline Utilization & -0.02 & 0.02 & 0.05 & 0.02 & -2.35 & 387 & $0.019^{*}$ & 0.12 \\
\hline Preservation & -0.08 & 0.04 & 0.17 & 0.06 & -3.45 & 387 & $0.006^{* *}$ & 0.17 \\
\hline \multicolumn{9}{|l|}{ Science motivation } \\
\hline Intrinsic motivation & 0.11 & 0.05 & -0.22 & 0.10 & 2.89 & 194.26 & $0.004^{* *}$ & 0.20 \\
\hline Career motivation & 0.06 & 0.05 & -0.13 & 0.08 & 2.08 & 209.72 & $0.038^{*}$ & 0.14 \\
\hline Self-determination & 0.02 & 0.05 & -0.05 & 0.10 & 0.66 & 205.74 & 0.508 & \\
\hline Self-efficacy & 0.13 & 0.05 & -0.26 & 0.10 & 3.46 & 185.16 & $0.002^{* *}$ & 0.25 \\
\hline Grade motivation & 0.08 & 0.05 & -0.16 & 0.09 & 2.26 & 198.05 & $0.024^{*}$ & 0.16 \\
\hline
\end{tabular}

\subsection{Measuring Science Motivation}

The science motivation model (2) with its five sub-scales, as presented by Glynn et al. [9], showed good fit indices, which are also presented in Table 1. All items loaded significantly onto their latent variable with standardized factor loadings ranging from 0.54 to 0.88 (see Figure 2). There were also significant $(p<0.001)$ positive interrelations among all five latent factors (see Table 3 ). Despite the strong covariance, all factors were statistically distinguishable. 


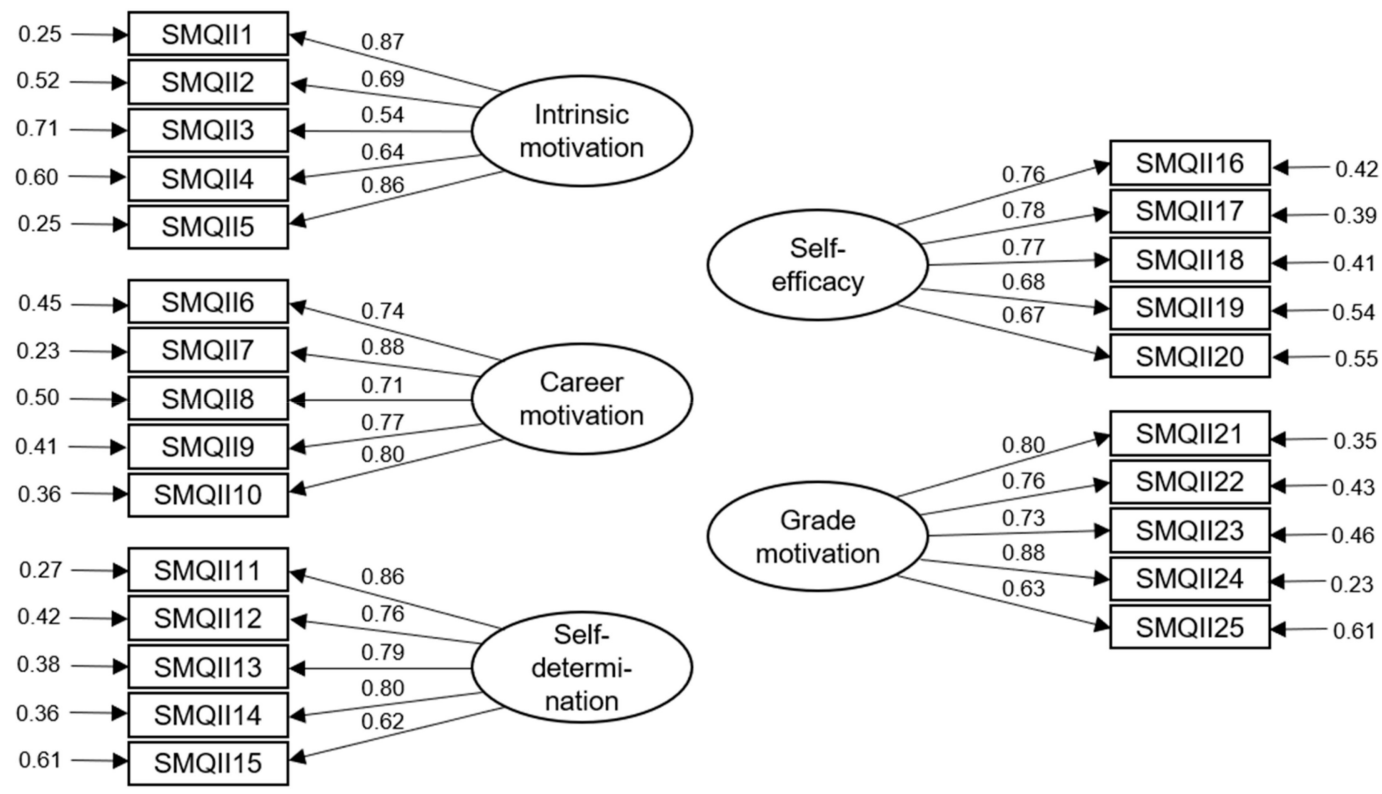

Figure 2. Confirmatory factor analysis of the Science Motivation Questionnaire in its current version (SMQ-II) with standardized factor loadings.

Table 3. Covariance between all five of SMQ-II's latent factors in the confirmatory factor analysis (CFA) (standardized scores).

\begin{tabular}{|c|c|c|c|c|c|}
\hline Science Motivation & Intrinsic Motivation & Career Motivation & Self-Determination & Self-Efficacy & Grade Motivation \\
\hline Intrinsic motivation & 1.00 & $0.71^{* * *}$ & $0.61^{* * *}$ & $0.67^{* * *}$ & $0.65^{* * *}$ \\
\hline Career motivation & & 1.00 & $0.54^{* * *}$ & $0.60^{* * *}$ & $0.62^{* * *}$ \\
\hline Self-determination & & & 1.00 & $0.71^{* * *}$ & $0.77^{* * *}$ \\
\hline Self-efficacy & & & & 1.00 & $0.76^{* * *}$ \\
\hline Grade motivation & & & & & 1.00 \\
\hline
\end{tabular}

According to Kline [46], the sub-scales showed good reliability with Cronbach's alpha from 0.83 (intrinsic motivation), 0.85 (self-efficacy), 0.87 (self-determination), 0.87 (grade motivation), to 0.88 (career motivation). Girls and boys differed significantly with respect to intrinsic motivation and self-efficacy, whereby boys respectively scored higher (Table 2). In contrast, girls scored lowest in self-efficacy and intrinsic motivation (see Table 2).

\subsection{Science Motivation and Environmental Values}

In order to explore the relationship between science motivation and environmental values, we described two path models-one model with science motivation as predictor for environmental values (model A) and an analogue model in which motivational aspects were predicted by environmental attitudes (model B). As displayed in Figure 3, model A showed sufficient a model fit to the data, although the $p$-value was less than $p<0.05$. We found the second-order factor science motivation as a predictor for the environmental values appreciation $(\beta=0.25, p<0.001)$ and preservation ( $\beta=0.23, p=0.003$ ), but not for utilization $(\beta=-0.17, p<0.001$ ). The analogue model (model B) showed similar fit indices, which can be accepted (Figure 4 ). In this model, environmental values as a higher order factor were mainly manifested by the first-order latent variables $\operatorname{APR}(\lambda=0.71, p<0.001)$ and PRE $(\lambda=0.62, p=0.001)$, but not by UTL $(\lambda=-0.04, p=0.709)$. In contrast to the previous model, positive environmental values predicted intrinsic motivation to learn science $(\beta=0.43, p=0.002)$, career motivation ( $\beta=0.34, p=0.020)$, self-determination $(\beta=0.35, p=0.007)$, and grade motivation $(\beta=0.30, p=0.013)$ with a higher amount of explained variance (see Figures 3 and 4 ). 


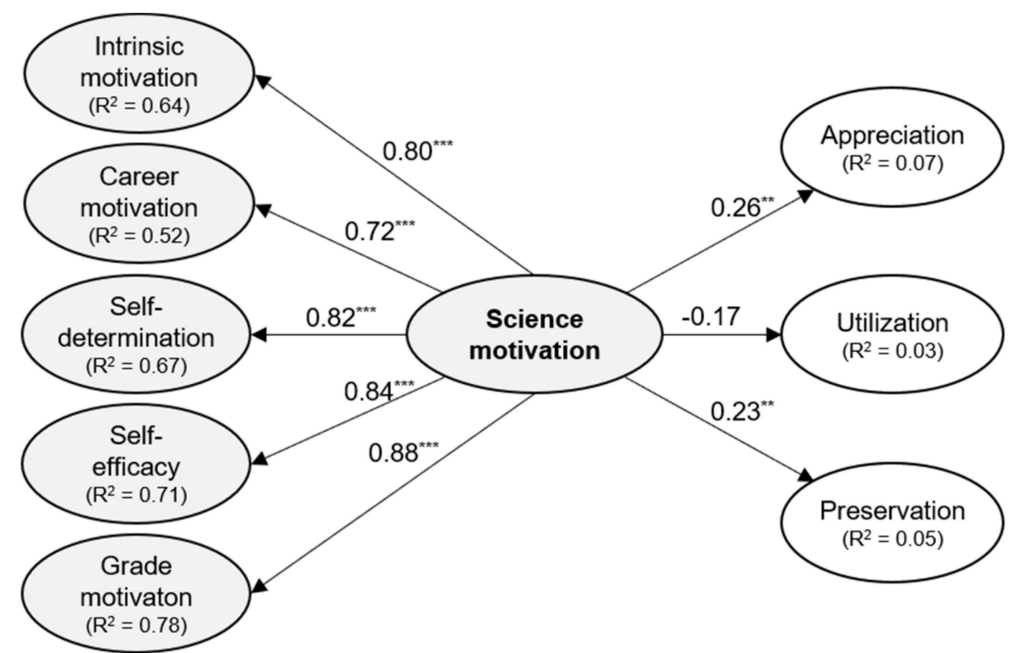

Model A: chi2 $=1188.340, d f=729$, chi2 $/ d f=1.63 . p<0.001, C F I=0.92$, RMSEA $=0.045, S R M R=0.062$

Figure 3. Path model with standardized regression coefficients of science motivation as a predictor for environmental values; ${ }^{* * *} p<0.001,^{* *} p \leq 0.01^{*} p \leq 0.05$.

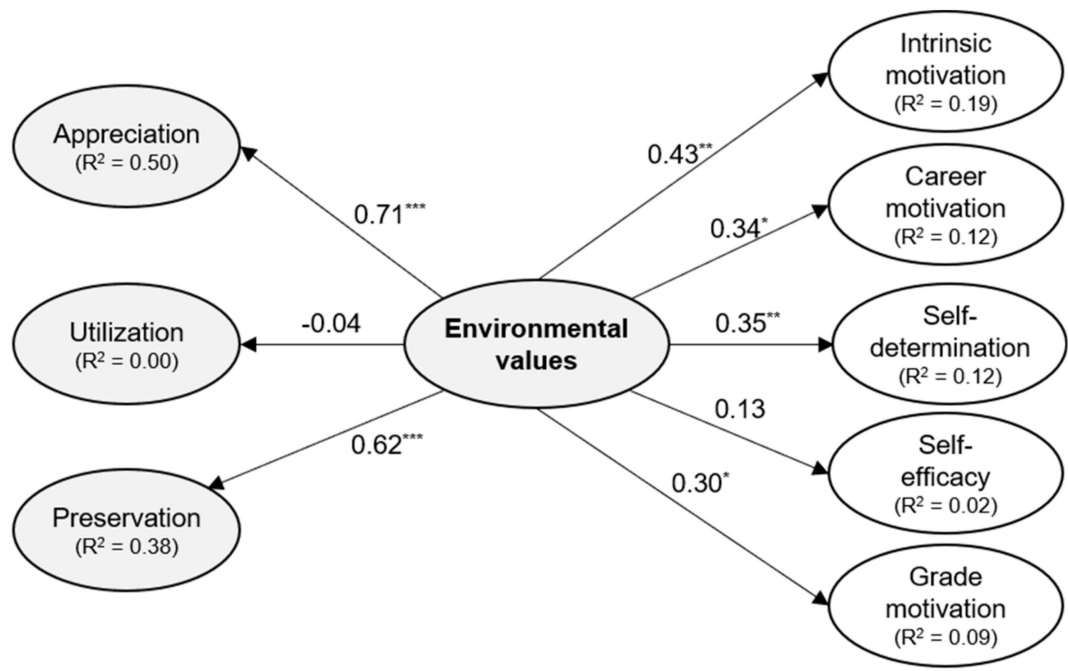

Model B: chi2 $=1146.001, d f=722, p<0.001, C F I=0.93$, RMSEA $=0.043$, $S R M R=0.059$

Figure 4. Path model with standardized regression coefficients of environmental attitudes as predictor for science motivation; ${ }^{* * *} p<0.001,^{* *} p \leq 0.01^{*} p \leq 0.05$.

\section{Discussion}

As mentioned before, the teaching of environmental issues is often embedded within formal science education, where students' motivation to learn science is declining, especially when students shift to secondary school $[7,8]$. Against the background of whether environmental education is still justifiably situated in science education, there is a lack of studies investigating possible synergies between both educational efforts [4]. The present study monitored the motivation to learn science and environmental values in order to provide advice for planning appropriate and target-group-oriented educational initiatives. 


\subsection{Students' Motivation to Learn Science}

Our analysis clearly proves the SMQ-II as a valid and reliable tool for its use at secondary-school level by validating the hypothesized five-component model derived from Glynn et al. [9]. This result is in line with the work of Schumm and Bogner [17], showing its suitability for German secondary-school students by using an exploratory factor analysis. This is an important argument as the scale was originally developed for assessing science motivation at university level. The scale was adapted and validated repeatedly. In fact, the motivation toward sciences has been further adapted, for instance, to specific science subjects, such as biology [47] or chemistry [48]. Similarly, different language versions were described, for instance, German [17], Greek [18], and Spanish [49]. Our CFA supported the original model as all extractions by the factor loadings of the motivational components were satisfactorily high, even higher than in Glynn et al. [9]. 'Potential shortcomings of the instrument' [17] (p. 440) in regard to misfits of the sub-scales 'grade motivation' and 'self-determination' could not be detected, maybe due to language differences. Our analyses showed that all sub-scales were positively related, which is also consistent with previous studies. However, in contrast to Glynn et al. [9] the interaction between the motivational factors in our study was much higher, especially the interaction of 'grade motivation'. A potential reason for the higher interaction within the motivational factors in our study may lie in the chosen age group. Although the factors were statistically distinguishable, they may mutually influence each other. In fact, a younger student is motivated to learn science in order to get a good grade, which accompanies or even influences his or her intrinsic motivation toward science. In contrast, a college student may be intrinsically motivated to learn science but is not necessarily motivated to get a good grade. Within the younger age group, this finding was already discussed by Lepper, Corpus, and Iyengar [50]. Comparing our analysis with the work of Schumm and Bogner [17], who also applied the scale to secondary school, our reliability analyses rendered similar Cronbach's alpha.

When assessing students' motivation toward science, we especially noticed a gender difference. In our study, boys had a significantly higher self-efficacy than girls had, which is in line with previous studies $[9,17]$. Following the social learning theory [51], the success of a role model similar to ourselves, in regard to learning science, seems to be transferred to the belief in someone's own capabilities. A gender specific self-efficacy may therefore result, as male role models in science are presumed to be the 'successful gender' [52]. Other explanations in this context employ parents' acknowledgement and support of their children's academic success often underestimating a daughter's competence in science [53]. As gender differences in science motivation are strongly influenced by social aspects such as teachers, parents, peers, role modelling, or media [9], it is of importance to strengthen efforts to support girls by providing more feedback or planning tailored educational initiatives. Contrary to previous studies using the SMQ-II, we also found girls to have a significantly lower intrinsic motivation to learn science. Reasons for that fact could be the imbalance between participating girls and boys in our study, but it could also be the younger age group compared to the literature. Similar to the appearance of girls' lower self-efficacy, their lower intrinsic motivation may also result from social aspects, as outlined above. This assumption could be strengthened by the strong correlation between self-efficacy and intrinsic motivation and the fact that boys scored highest and girls lowest in both motivational aspects. We make the same assumption for the slight gender difference regarding extrinsic motivation (grade and career motivation).

Keeping the decline of secondary school students' science motivation in mind, it is of interest to focus on specific motivational aspects. According to the literature $[9,17,54]$, students are more motivated toward science by external goals, such as good grades, than by internal goals. We can support that fact when looking at girls' low intrinsic motivation. Unfortunately, grades may gain too much importance in regular educational systems. Supporting more internal goals, and thus intrinsic motivation, interest, and curiosity, need to be fostered by appropriate learning approaches, in particular, concerning the support of girls' science motivation. While boys perceived a relatively high self-efficacy and intrinsic motivation, their reported self-determination was a weak factor within students' motivation to learn science. Unfortunately, evaluation and surveillance as well as deadline and threats, which are common 
in classrooms, compel self-determination. Therefore, teachers should be sensitive in counteracting these trends by giving more positive feedback and allowing more choices [12].

\subsection{Students' Environmental Values}

The Two-Major Environmental Values scale, originally established by Bogner and Wiseman [33,34] was repeatedly confirmed in different countries, languages, and age groups (for a current overview see [36]). This was also true when the applied scale was accompanied by appreciation of nature [37], balancing the previously one-sided view of utilization. Conducting an exploratory factor analysis, the published factor solution of preservation and utilization appeared even when appreciation was included [36]. Therefore, we see an approval of the model when conducting a CFA. The three-factor structure was the statistically best solution contributing to the construct validity of the expanded 2-MEV model. All applied items loaded sufficiently on the respective factors.

The CFA unveiled only one significant interrelation between the 'positive' attitudinal factors. While appreciation of nature and preservation seem to be strongly related, exploitative utilization stands detached. In line with the literature, it is not surprising that people who tend to preserve the environment also enjoy and appreciate nature for personal gains and vice versa [35,55]. The detached utilization factor retrieved from the original 2-MEV model was in some earlier studies negatively correlated with the orthogonal factor preservation $[34,56]$, whereas other studies only report weak or even no interrelations [36]. Besides the fact that different values were used as the basis for correlations (CFA vs. EFA), further explanations for that inconsistency may root in the heterogeneity of the samples and the adjustment of the scale. As summarized by Bogner [36], the 2-MEV instrument was applied to multiple age groups with different social backgrounds as well as in diverse languages with a varying number of items (currently, 32 language applications are known). For instance, the reduction of item numbers may have led to the diminished interrelation in the hypothesized model. When considering the acceptable internal consistency of each sub-scale, the underlying model constitutes a reliable and valid instrument to assess peoples' environmental value system regarding preservation, exploitative utilization, and now even appreciation of nature.

The fact that girls tend to have a more positive attitude toward nature is in line with the majority of literature, which mostly observed females showing more eco-friendly perspectives [57,58]. Being aware of students' specific attitude sets and perspectives may help for planning and preparing adequate educational modules in order to reach more students appropriately. Keeping the interrelations between the sub-scales in mind, learning approaches may thereby focus on supporting the appreciation of nature as an emphasis to encourage pro-environmental behavior.

\subsection{Relationship between Science Motivation and Environmental Values}

Positive environmental values (preservation, appreciation of nature) clearly appear to be associated with the motivation to learn science. This pattern was found for almost all specific motivational aspects when taking a closer look. Especially the intrinsic motivation seems to be affected. This may lie in the simple fact that students with a strong interest in environmental topics may perceive inherent pleasure in dealing with these and tend to be more intrinsically motivated with regard to science in general. Individual interest may provide the precondition for motivation, especially for intrinsic motivation [59]. Similarly, for adolescents' self-determination, career and grade motivation seem to be predicted by environmental concerns. Drawing conclusions from this relationship, high scorers in 'green' attitudes also tend to be more motivated to learn science. Thus, appreciating and preserving nature may enable adolescents entering the world of science. Delving into environmental topics may lead to an intrinsic motivation to engage with science-related issues. While the feeling of autonomy (self-determination) is apparently associated with environmental attitudes, the perceived self-confidence in accomplishing a scientific task (self-efficacy) is not a predictor. This is not surprising, as 'green' attitudes may not intervene with related learning strategies. Extrinsic motivational aspects like grade and career motivation may find support as a side effect. Even though there are no comparable 
research findings on the influence of environmental attitude sets on motivation, environmental-friendly attitudes help adolescents to acquire new knowledge [32]. Using our results from that angle for educational purposes, students can be motivated to learn science in general by addressing them through environmental education. One of the aims of environmental education is to foster a positive attitude to preserving nature [5], which may lead to an overall high level of motivation in science education. Due to the existing gender difference regarding green preferences, girls' science motivation may be addressed in particular through environmental topics.

Considering the results from another perspective (model A), students' science motivation acts as a predictor for positive environmental values (appreciation and preservation). Being motivated to learn science is known to intervene with cognitive achievement $[13,20]$, also in the environmental context [19]. Dealing intensively with environmental topics and, thus, high performance may lead to positive environmental attitudes [25]. Considering this perspective, learning approaches in science education should strengthen students' science motivation in order to contribute to someone's 'green' attitude and his or her environmental behavior in the long term. Turning the tables concerning gender differences, male adolescents with an evident higher level of science motivation $[7,8]$ could strengthen their environmental preferences through science education. Environmental topics with a more science \& technology-related background may support that linkage.

No matter from which point of view, the association between environmental attitudes and the motivation to learn science needs to receive further investigation. A suggested next step could be the examination of appropriate learning initiatives in regular science classes. Do environmental-content-related lessons contribute to motivation, attitude, and interest toward science?

\section{Conclusions}

High preservative and appreciative preferences toward nature are aligned with a high level of motivation to learn science. This relation points to promising synergies between science education and environmental education. When planning and implementing educational initiatives, both efforts can enrich each other-especially the intrinsic motivation to learn science may find support by environmental issues fostering 'green' attitudes. This may be of particular relevance to students (especially girls) with a supposedly lower motivation to learn science. Moreover, this finding responds to the need for supporting internal goals, rather than relying on external goals such as grade motivation. Against the background of the declining motivation in formal science education, environmental topics can act as door opener in science classes. Environmental issues should be not considered as separate learning content or digressions, they should rather be more integrated in the learning process in science education. Global environmental problems can function as tangible anchors that need to be solved, and which are worth learning about in order to become a scientific literate citizen. In this way, a student may be 'moved to learn science'.

On the other hand, science education focusing on environmental issues can support students' preferences of appreciating and preserving nature. Especially boys may be addressed in this way. Approaches emphasizing environment and science and technology (such as citizen science) may offer beneficial opportunities, creating a synergy between environmental and science education. Scientific and technical contributions and solutions are crucial in order to counteract current wicked challenges. Students with a high level of science motivation should be encouraged to use that motivation, as well as their scientific understanding and positive attitudes, to contribute to the world's major challenges. In light of current developments on a global level, such as the adoption of the Agenda 2030 by the United Nations [60], both efforts may finally deal with the same challenges and work together for a sustainable future-supporting one will also support the other.

Author Contributions: Conceptualization, M.L.S.; data curation, M.L.S.; formal analysis, M.L.S.; funding acquisition, F.X.B.; investigation, M.L.S.; methodology, M.L.S.; project administration, F.X.B.; resources, F.X.B.; 
software, F.X.B.; supervision, F.X.B.; visualization, M.L.S.; writing-original draft, M.L.S.; writing一review and editing, F.X.B. All authors have read and agreed to the published version of the manuscript.

Funding: This research was funded by the "MINT-Lehramt PLUS" program of the "Elitenetzwerk Bayern" (ENB) under grant agreement no. S-NW-2015-316. The APC was funded by the German Research Foundation (DFG) and the University of Bayreuth under the funding program Open Access Publishing under grant agreement no. LA 2159/8-6. The funders had no role in the design of the study, in the collection, analyses, or interpretation of data, in the writing of the manuscript, or in the decision to publish the results. This article reflects only the authors views. The ENB and the DFG are not liable for any use that might be made of the information contained herein.

Acknowledgments: The authors are very grateful to all students and their teachers for the cooperation in our study as well as to P. Raab, T. Blaine, and M. Farren for collecting the data. We also thank M. Schumm for discussing earlier stages of our paper.

Conflicts of Interest: The authors declare no conflict of interest.

\section{References}

1. Dillon, J. 50 Years of JBE: From Science and Environmental Education to Civic Science. J. Biol. Educ. 2016, 50, 120-122. [CrossRef]

2. Wals, A.E.J.; Brody, M.; Dillon, J.; Stevenson, R.B. Convergence between science and environmental education. Science 2014, 344, 583-584. [CrossRef] [PubMed]

3. Gough, A. The emergence of environmental education research. In International Handbook of Research on Environmental Education; Routledge: New York, NY, USA, 2013; pp. 13-23.

4. Gough, A. Mutualism: A different agenda for environmental and science education. Int. J. Sci. Educ. 2002, 24, 1201-1215. [CrossRef]

5. UNESCO. The Belgrade charter on environmental education. Connect UNESCO-UNEP Environ. Educ. Newsl. 1976, 6, 135-136.

6. UNESCO; UNEP. The Tbilisi Declaration. In Intergovernmental Conference on Environmental Education; UNESCO: Tbilisi, Georgia, 1977; pp. 14-26.

7. Osborne, J.; Simon, S.; Collins, S. Attitudes towards science: A review of the literature and its implications. Int. J. Sci. Educ. 2003, 25, 1049-1079. [CrossRef]

8. Potvin, P.; Hasni, A. Interest, motivation and attitude towards science and technology at K-12 levels: A systematic review of 12 years of educational research. Stud. Sci. Educ. 2014, 50, 85-129. [CrossRef]

9. Glynn, S.M.; Brickman, P.; Armstrong, N.; Taasoobshirazi, G. Science motivation questionnaire II: Validation with science majors and nonscience majors. J. Res. Sci. Teach. 2011, 48, 1159-1176. [CrossRef]

10. Bandura, A. Social Foundations of Thought and Action: A Social Cognitive Theory; Prentice-Hall, Inc.: Upper Saddle River, NJ, USA, 1986; ISBN 013815614X.

11. Ryan, R.M.; Deci, E.L. Intrinsic and Extrinsic Motivations: Classic Definitions and New Directions. Contemp. Educ. Psychol. 2000, 25, 54-67. [CrossRef]

12. Schunk, D.H.; Pintrich, P.R.; Meece, J.R. Motivation in Education: Theory, Research, and Applications; Pearson/Merrill Prentice Hall: Upper Saddle River, NJ, USA, 2008; ISBN 9780132281553.

13. Black, A.E.; Deci, E.L. The Effects of Instructors' Autonomy Support and Students' Autonomous Motivation on Learning. Sci. Educ. 2000, 84, 740. [CrossRef]

14. Pajares, F. Gender and perceived self-efficacy in self-regulated learning. Theory Pract. 2002, 41, 116-125. [CrossRef]

15. Lovelace, M.; Brickman, P. Best practices for measuring students' attitudes toward learning science. CBE Life Sci. Educ. 2013, 12, 606-617. [CrossRef] [PubMed]

16. Deci, E.L.; Ryan, R.M. Self-determination theory: A macrotheory of human motivation, development, and health. Can. Psychol. 2008, 49, 182-185. [CrossRef]

17. Schumm, M.F.; Bogner, F.X. Measuring adolescent science motivation. Int. J. Sci. Educ. 2016, 38, 434-449. [CrossRef]

18. Salta, K.; Koulougliotis, D. Assessing motivation to learn chemistry: Adaptation and validation of Science Motivation Questionnaire II with Greek secondary school students. Chem. Educ. Res. Pract. 2015, 16, 237-250. [CrossRef]

19. Schumm, M.F.; Bogner, F.X. The impact of science motivation on cognitive achievement within a 3-lesson unit about renewable energies. Stud. Educ. Eval. 2016, 50, 14-21. [CrossRef]

20. Singh, K.; Granville, M.; Dika, S. Mathematics and Science Achievement: Effects of Motivation, Interest, and Academic Engagement. J. Educ. Res. 2002, 95, 323-332. [CrossRef] 
21. Velayutham, S.; Aldridge, J.; Fraser, B. Development and validation of an instrument to measure students' motivation and self-regulation in science learning. Int. J. Sci. Educ. 2011, 33, 2159-2179. [CrossRef]

22. Zeyer, A. Motivation to Learn Science and Cognitive Style. Eurasia J. Math. Sci. Technol. Educ. 2010, 6, 121-128. [CrossRef]

23. Tuan, H.L.; Chin, C.C.; Shieh, S.H. The development of a questionnaire to measure students' motivation towards science learning. Int. J. Sci. Educ. 2005, 27, 639-654. [CrossRef]

24. Potter, G. Environmental Education for the 21st Century: Where Do We Go Now? J. Environ. Educ. 2009, 41, 22-33. [CrossRef]

25. Roczen, N.; Kaiser, F.G.; Bogner, F.X.; Wilson, M. A competence model for environmental education. Environ. Behav. 2014, 46, 972-992. [CrossRef]

26. Mayer, F.S.; Frantz, C.M.P. The connectedness to nature scale: A measure of individuals' feeling in community with nature. J. Environ. Psychol. 2004, 24, 503-515. [CrossRef]

27. Varela-Losada, M.; Vega-Marcote, P.; Pérez-Rodríguez, U.; Álvarez-Lires, M. Going to action? A literature review on educational proposals in formal Environmental Education. Environ. Educ. Res. 2016, 22, 390-421. [CrossRef]

28. Fančovičová, J.; Prokop, P. Plants have a chance: Outdoor educational programmes alter students' knowledge and attitudes towards plants. Environ. Educ. Res. 2011, 17, 537-551. [CrossRef]

29. Schönfelder, M.L.; Bogner, F.X. Two ways of acquiring environmental knowledge: By encountering living animals at a beehive and by observing bees via digital tools. Int. J. Sci. Educ. 2017, 39, 723-741. [CrossRef]

30. Bogner, F.X. The influence of short-term outdoor ecology education on long-term variables of environmental perspective. J. Environ. Educ. 1998, 29, 17-29. [CrossRef]

31. Johnson, B.; Manoli, C.C. The 2-MEV Scale in the United States: A measure of children's environmental attitudes based on the theory of ecological attitude. J. Environ. Educ. 2010, 42, 84-97. [CrossRef]

32. Fremerey, C.; Bogner, F.X. Cognitive learning in authentic environments in relation to green attitude preferences. Stud. Educ. Eval. 2015, 44, 9-15. [CrossRef]

33. Bogner, F.X.; Wiseman, M. Adolescents' attitudes towards nature and environment: Quantifying the 2-MEV model. Environmentalist 2006, 26, 247-254. [CrossRef]

34. Bogner, F.X.; Wiseman, M. Toward Measuring Adolescent Environmental Perception. Eur. Psychol. 1999, 4, 139-151. [CrossRef]

35. Kibbe, A.; Bogner, F.X.; Kaiser, F.G. Exploitative vs. appreciative use of nature-Two interpretations of utilization and their relevance for environmental education. Stud. Educ. Eval. 2014, 41, 106-112. [CrossRef]

36. Bogner, F.X. Environmental Values (2-MEV) and Appreciation of Nature. Sustainability 2018, 10, 350. [CrossRef]

37. Brügger, A.; Kaiser, F.G.; Roczen, N. One for All? Eur. Psychol. 2011, 16, 324-333. [CrossRef]

38. Raab, P.; Randler, C.; Bogner, F. How Young “Early Birds" Prefer Preservation, Appreciation and Utilization of Nature. Sustainability 2018, 10, 4000. [CrossRef]

39. Beauducel, A.; Wittmann, W.W. Simulation Study on Fit Indexes in CFA Based on Data with Slightly Distorted Simple Structure. Struct. Equ. Model. A Multidiscip. J. 2005, 12, 41-75. [CrossRef]

40. Browne, M.W.; Cudeck, R. Alternative Ways of Assessing Model Fit. Sociol. Methods Res. 1992, 21, 230-258. [CrossRef]

41. Hooper, D.; Coughlan, J.; Mullen, M. Structural equation modelling: Guidelines for determining model fit. Electron. J. Bus. Res. Methods 2008, 6, 53-59.

42. Field, A.; Miles, J.; Field, Z. Discovering Statistics Using R, 1st ed.; SAGE Publications, Ltd.: London, UK, 2012; ISBN 978-1-4462-0045-2.

43. Cohen, J. A power primer. Psychol. Bull. 1992, 112, 155-159. [CrossRef]

44. Bagozzi, R.P.; Yi, Y. Specification, evaluation, and interpretation of structural equation models. J. Acad. Mark. Sci. 2012, 40, 8-34. [CrossRef]

45. Gatignon, H. Statistical Analysis of Management Data; Springer: New York, NY, USA, 2010; ISBN 978-1-4419-1269-5.

46. Kline, P. The Handbook of Psychological Testing/Paul Kline; Routledge: London, UK, 1999; ISBN 00071269.

47. Cleveland, L.M.; Olimpo, J.T.; DeChenne-Peters, S.E. Investigating the relationship between instructors' use of active-learning strategies and students' conceptual understanding and affective changes in introductory biology: A comparison of two active-learning environments. CBE Life Sci. Educ. 2017, 16, 1-10. [CrossRef]

48. Austin, A.C.; Hammond, N.B.; Barrows, N.; Gould, D.L.; Gould, I.R. Relating motivation and student outcomes in general organic chemistry. Chem. Educ. Res. Pract. 2018, 19, 331-341. [CrossRef] 
49. Ardura, D.; Pérez-Bitrián, A. The effect of motivation on the choice of chemistry in secondary schools: Adaptation and validation of the Science Motivation Questionnaire II to Spanish students. Chem. Educ. Res. Pract. 2018, 19, 905-918. [CrossRef]

50. Lepper, M.R.; Corpus, J.H.; Iyengar, S.S. Intrinsic and extrinsic motivational orientations in the classroom: Age differences and academic correlates. J. Educ. Psychol. 2005, 97, 184-196. [CrossRef]

51. Bandura, A. Social Learning Theory; Prentice Hall: Englewood Cliffs, NJ, USA, 1977.

52. Ceci, S.; Williams, W. Why Aren't More Women in Science. Top Researchers Debate the Evidence; American Psychological Association: Washington, DC, USA, 2007.

53. Meece, J.L.; Courtney, D.P. Gender Differences in Students' Percepions: Consequences for Achievement-Related Choices. In Student Perceptions in the Classroom; Lawrence Erlbaum Associates: Hillsdale, NJ, USA, 1992; pp. 209-228.

54. Vedder-Weiss, D.; Fortus, D. Adolescents' declining motivation to learn science: A follow-up study. J. Res. Sci. Teach. 2012, 49, 1057-1095. [CrossRef]

55. Kaiser, F.G.; Hartig, T.; Brügger, A.; Duvier, C. Environmental Protection and Nature as Distinct Attitudinal Objects: An Application of the Campbell Paradigm. Environ. Behav. 2013, 45, 369-398. [CrossRef]

56. Schneller, A.J.; Johnson, B.; Bogner, F.X. Measuring children's environmental attitudes and values in northwest Mexico: Validating a modified version of measures to test the Model of Ecological Values (2-MEV). Environ. Educ. Res. 2015, 21, 61-75. [CrossRef]

57. Zelezny, L.; Chua, P.; Aldrich, C. Elaborating on Gender Differences in Environmentalism. J. Soc. Issues 2000, 56, 443-457. [CrossRef]

58. Milfont, T.L.; Duckitt, J. The structure of environmental attitudes: A first- and second-order confirmatory factor analysis. J. Environ. Psychol. 2004, 24, 289-303. [CrossRef]

59. Hidi, S.; Harackiewicz, J.M. Motivating the Academically Unmotivated: A Critical Issue for the 21st Century. Rev. Educ. Res. 2007, 70, 151-179. [CrossRef]

60. UN General Assembly. Transforming Our World: The 2030 Agenda for Sustainable Development. A/RES/70/1; UN General Assembly: New York, NY, USA, 2015.

(C) 2020 by the authors. Licensee MDPI, Basel, Switzerland. This article is an open access article distributed under the terms and conditions of the Creative Commons Attribution (CC BY) license (http://creativecommons.org/licenses/by/4.0/). 